\title{
ASSOCIATIONS BETWEEN FLIES AND SPIDERS: BIBIOCOMMENSALISM AND DIPSOPARASITISM?*
}

\author{
BY \\ MICHAEL H. RoBINSON AND BARBARA RoBINSON \\ Smithsonian Tropical Research Institute \\ P.O. Box 2072, Balboa, Canal Zone, Panama
}

There are numerous records in the arachnological and entomological literature of relationships between spiders and flies other than the simple case of predator and prey. Bristowe (1941:362-370) reviewed a number of cases of parasitism and commensalism. Flies of the superfamily Drosophiloidea are involved in a number of more or less complex relationships with spiders. Chloropids parasitize spiders' egg cocoons and may actually perch on adult spiders (Bristowe, 1941:367) while milichiids share food with spiders (Richards, 1953). McMillan (1975) has recorded an association between milichiid flies of the genus Desmometopa and two species of large Australian orb-weaving spiders. The flies moved about the host web and fed on prey items as they were being consumed by the spiders. In addition, the milichiid moved onto the host and apparently cleaned the mouthparts and anal region of the spider. McMillan does not state whether the flies remained on the spiders when they were not actively cleaning them nor does he state how many flies were present on the spider at any one time. We here report on several different associations between flies and spiders, all of which are commensal (in the broadest sense). We found milichiids associated with the golden-web spider Nephila clavipes, unidentified flies were found as commensals of Argiope savignyi, and chloropid flies were found in a similar relationship with Argiope argentata. All these relationships were discovered in Panama. We describe a case of milichiid commensalism with a predatory hemipteran and suggest that the complex relationship between Nephila and the milichiids may have evolved from such a relatively simple stage. We think that the term commensalism is not sufficiently specific to describe some of the relationships reviewed here and suggest two possible additions to the terminology of symbioses.

*Manuscript received by the editor October 31, 1977. 


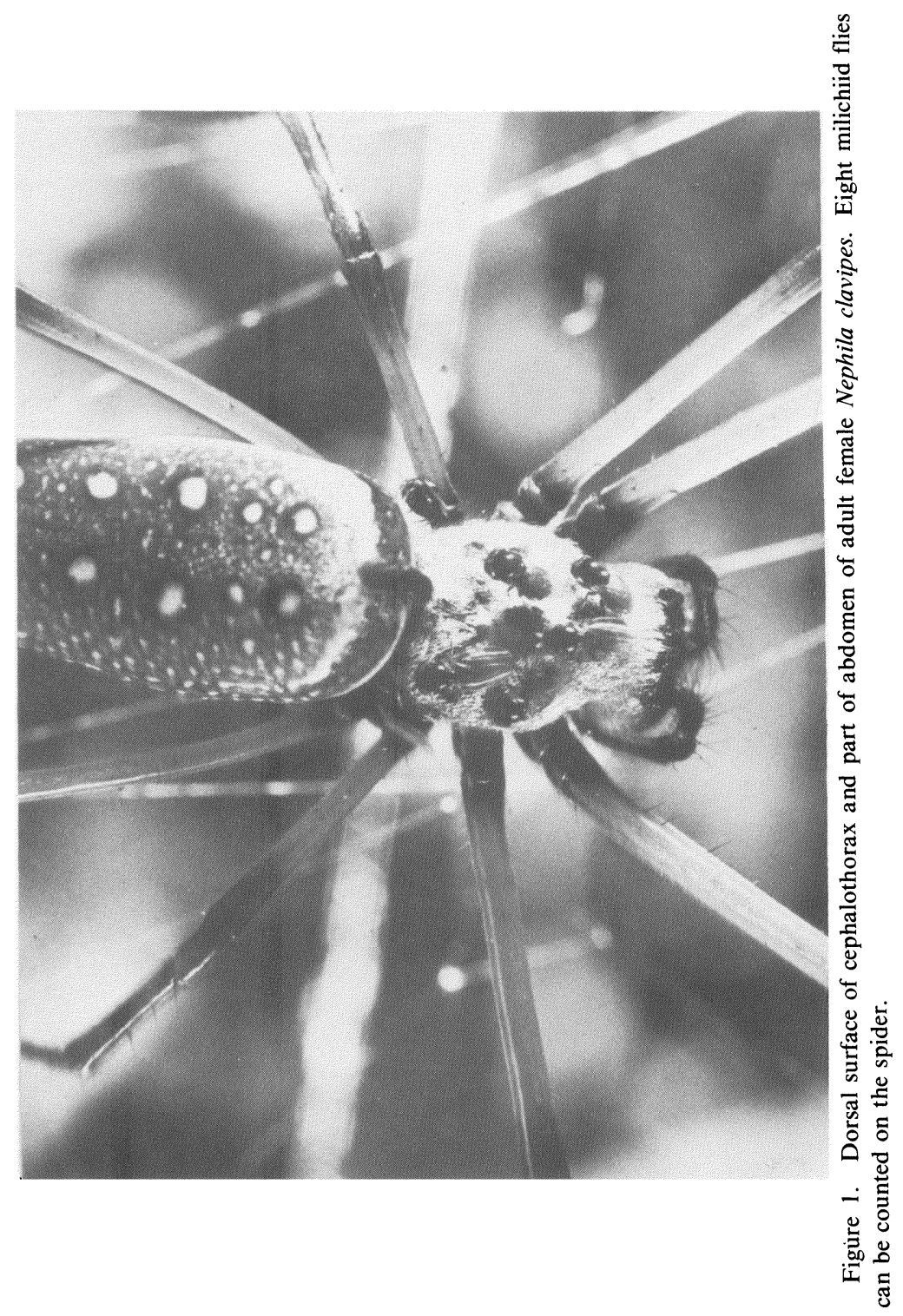


Nephila clavipes and flies of the genus Phyllomyza

We first found flies associated with Nephila clavipes in January 1976, on Barro Colorado Island, Canal Zone, Panama. We subsequently found similar flies associated with this spider at a number of localities in the Canal Zone and elsewhere in Panama. Flies from four adult female $N$. clavipes at four different sites were collected. They were identified (see acknowledgments) as belonging to the genus Phyllomyza and all belonging to the same (undetermined) species. All eleven insects were females. The flies rest on the dorsal surface of the spider and usually aggregate on the cephalothorax. Figure 1 shows eight flies resting on this area. The flies remain on the spider for long periods of time and are virtually inactive. When we set out to determine what the flies were doing sitting on the body of the spider we ran into a major practical problem. The Drosophila-sized flies were really too small to observe with the unaided eye. This problem was solved by adapting a stereo-binocular microscope for horizontal use, mounted on a camera tripod (Robinson \& Smythe, 1976). With this device, under field conditions we could watch the insects under $10 \times$ or $20 \times$ magnification. It became apparent that on the cephalothorax of the spider the flies were not doing anything other than grooming themselves, sporadically shifting position and occasionally defecating. The bodies looked entirely normal and there was no evidence of oviposition or of penetrative feeding on the spider itself. (The mouthparts of milichiids could clearly not be used for piercing the spider's cuticle and sucking its internal fluids, but at this stage we did not know what the flies were.) Eventually we decided to feed the spider. This went through all phases of its predatory behavior without disturbance to the flies. Prey capture involved rushing out to attack the prey, biting it, wrapping it in silk, removing it from the web, transporting it back to the hub and there wrapping it once again before hanging it and feeding (details in Robinson \& Robinson, 1973, for Nephila maculata apply broadly to $N$. clavipes). This predatory sequence involves a great deal of violent movement, in space and of the spider's legs, throughout which the flies simply sat tight.

At the hub the spider passed secretions into the prey and after about eight minutes the whole surface of the insect was covered in a film of liquid. At this stage the flies left the body of the spider and clustered on the surface of its prey. There they could be seen 
dabbing at the liquid with their extended mouthparts. They quickly became swollen with food and their abdomens in particular were distended and almost spherical. The intersegmental membranes became very clearly visible and extended. After feeding the flies returned to the spider's cephalothorax. This timing of movement onto the prey item to coincide with its liquifaction seems to be fairly precise. It occurred in five out of five instances in which we provided the spider with prey and watched the whole process from its inception. The spider on which we made these observations disappeared after four days and we replaced it (on the still-intact web) with an adult female Argiope argentata. Two flies settled on this spider and fed once on her prey before disappearing. (It is noteworthy that the Argiope was able to locate and successfully attack prey on the structurally very different Nephila web. This has provided us with a useful tool for further studies of araneid predatory behavior.)

We saw very few cases where the spider reacted to the presence of the flies. Araneids seem to make very few responses to the activities of their larger kleptoparasitic associates, the theridiids of the genus Argyroides (see Robinson \& Olazarri, 1971:34-5; Robinson \& Robinson, 1973:32).

Argiope savignyi and unidentified flies

While carrying out observations on Argiope savignyi in an insectary at Curundu, Canal Zone, Panama, the prey of two separate adult female spiders was visited by flies that did not alight on the spider at any stage. The flies "appeared from nowhere" and fed on liquifying prey items from which the spider was simultaneously feeding. On one occasion the spider's prey was a pentatomid and the entire insectary in which we were working was flooded with the penetrating odor of the hemipteran's defensive secretion. In the second case (Figure 2), the prey was a moth. In both instances the flies alighted on the spider's prey and never moved onto the spider at any stage. After feeding they simply flew off. We were unable to catch the three flies involved.

\section{Argiope argentata and Conioscinella sp.}

While censusing Argiope argentata along the Old Gamboa Road, Summit, Canal Zone, we found an adult female of this species consuming a half-digested acridiid. On this prey were two small flies 


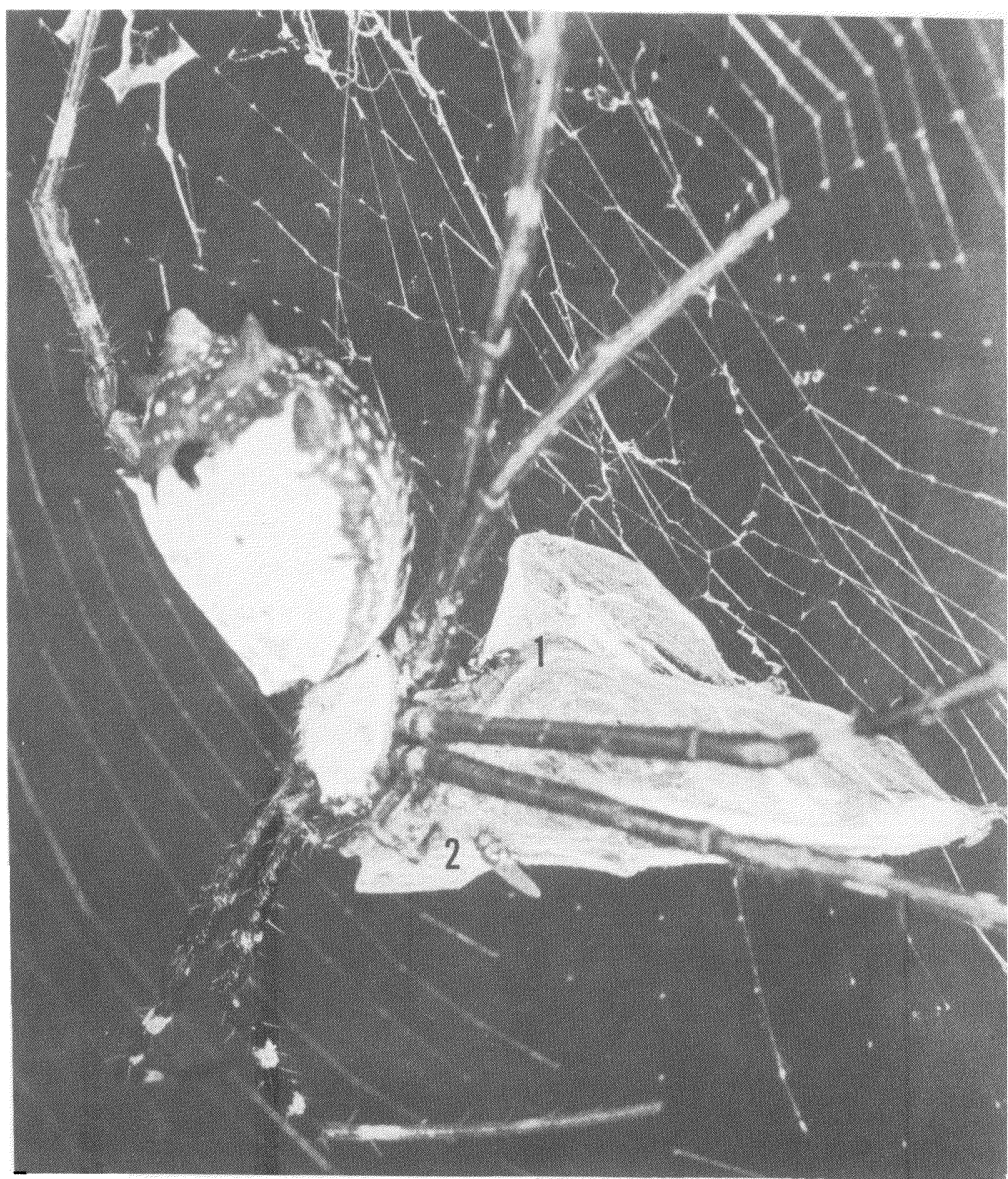

Figure 2. Argiope savignyi feeding on a moth, two flies (marked) are visible on the prey.

that we succeeded in collecting. They were identified as chloropids of the genus Conioscinella. Several species of chloropids are known to parasitize the egg cocoons of spiders (see, for instance, Bristowe, 1941:366-7).

Milichiids and a reduviid

At the La Fortuna dam site, Chiriqui, Panama, one of us (MHR) observed a reduviid Zelus trimaculatus Distant, feeding on a sting- 
less bee (Trigona cupira Sm.) which was impaled on the bug's proboscis. Around the prey item was a large number of small flies all apparently feeding. Eight of these flies were captured, many escaped. The flies were identified as Neophyllomyza sp.

\section{DISCUSSION}

The relationship between Phyllomyza sp. and its host Nephila clavipes is one that involves prolonged contact between the two species. We suspect that the same flies may remain on the spider for days at a time, leaving only to make very short feeding forays. Our attempts to paint-mark the tiny flies failed utterly so we cannot be certain on this point. In any case, the association seems to us to be distinctly more specialized than that described by McMillan (1975) for Desmometopa sp. Of course, this is a matter of interpretation. However, it is possible to suggest an evolutionary pathway from commensalism without contact (the reduviid and Argiope savignyi associates) through commensalism plus feeding excursions onto the host, to commensalism with sustained non-trophic contact. If the flies were cued into food sources by olfactory stimuli, as seems possible, then the pathway would involve a reduction of the detection distance. The strategy of waiting on the host must involve some interesting mechanism that allows the fly to "evaluate" the odds on food being available within its own feeding timescale. At some stage the fly may be faced with "deciding" whether to remain with a spider on the off-chance that it will catch food or using its remaining food reserves to fly off in search of another (more successful?) host. In this respect, the fly may be at an advantage over the kleptoparasitic theridiid spiders that also associate with $N$. clavipes. It can probably range over greater distances, more quickly, in search of a new host than can the spiders. At least three species of theridiids associate with the golden-web spider; at least one of these regularly shares the host's meal, at the hub of the web (Vollrath, in press). Such kleptoparasitic spiders are small, but differ from the milichiids in having mouthparts capable of penetrating insect cuticle.

Spiders of the genus Nephila may be particularly suitable as hosts for this kind of associate, They are large, build very efficient webs that are operated 24 hours per day, and show a considerable degree of web-site tenacity. The other large, diurnal, orb-web spi- 
ders in Panama build much more ephemeral webs that are more susceptible to damage (they are nothing like as strong). They probably spend much less time on their webs at any one site, a situation which may be less favorable to the development of a protracted association. The fact that the only time we have seen milichiids resting on an Argiope was when this spider had been placed on a Nephila web could indicate that the flies respond to some characteristic of the web in finding their hosts. On a recent trip to Papua New Guinea (May 1977), one of us (MHR) looked at over 500 adult Nephila maculata, hoping to find flies resting on the spider. None were found. Bristowe (1941:369) reports that R. N. Champion Jones saw a small fly crawl over the palps of Nephila maculata in India. Conceivably this is a case where a less sustained association has evolved.

As far as the milichiids are concerned it is at least possible that their relationship with Nephila may be more than a trophic one. The fact that all the Phyllomyza sp. that we collected were females is disturbing. The fact that we found Conioscinella feeding on the prey of Argiope argentata makes it possible that the egg parasites of araneids could also be commensals. The reverse could be true.

There is some problem about finding terms that accurately describe the relationship of the milichiids to their host(s). They are clearly commensals (in the broad sense) since they "share a table" with their hosts. However, they rely on the host liquifying the prey, they drink alongside the host and could perhaps be called bibiocommensals. The presence of fairly large numbers of flies feeding on a prey item could reduce the amount of food available to the host in a significant way, in which case the term parasite would be justifiable. A drinking parasite would be a dipsoparasite and this term is (to us) more euphonious than bibiocommensal.

\section{ACKNOWLEDGMENTS}

We thank the Insect Identification and Beneficial Insect Introduction Institute, USDA, Beltsville, Maryland (Chairman, Dr. L. Knutson), for identifying all the insects involved in this study. The experts involved were: C. W. Sabrosky, J. L. Herring, and S. W. Batra. Dr. Sabrosky drew our attention to a number of published works on the relationship between milichiids and spiders; this additional help is greatly appreciated. 


\section{REFERENCES}

BRISTOwE, W. S.: The comity of spiders. Volume 2. Ray Society, London 1941

McMill.AN, R. P.: Observations on flies of the family Milichiidae cleaning Araneus and Nephila spiders. West Australian Naturalist, 13: 96 (1965)

RichaRDS, O. W.: On commensalism of Desmometopa with predacious insects and spiders. Proc. roy. ent. Soc. (Lond.) Ser. C. 18: 55-56 (1953)

Robinson, M. H. AND OlazARRI, J.: Units of behavior and complex sequences in the predatory behavior of Argiope argentata (Fabricius): (Araneae: Araneidae). Smith. Contr. Zool. 65: 1-36 (1971)

Robinson, M. H. AND Robinson, B.: The ecology and behavior of the giant wood spider Nephila marculata (Fabricius) in New Guinea. Smith. Contr. Zool. 149: 1-76 (1973)

Robinson, M. H. AND SMYTHE, N.: A technique for observing the behavior of small animals under field conditions. Psyche 83: 210-212 (1976) 

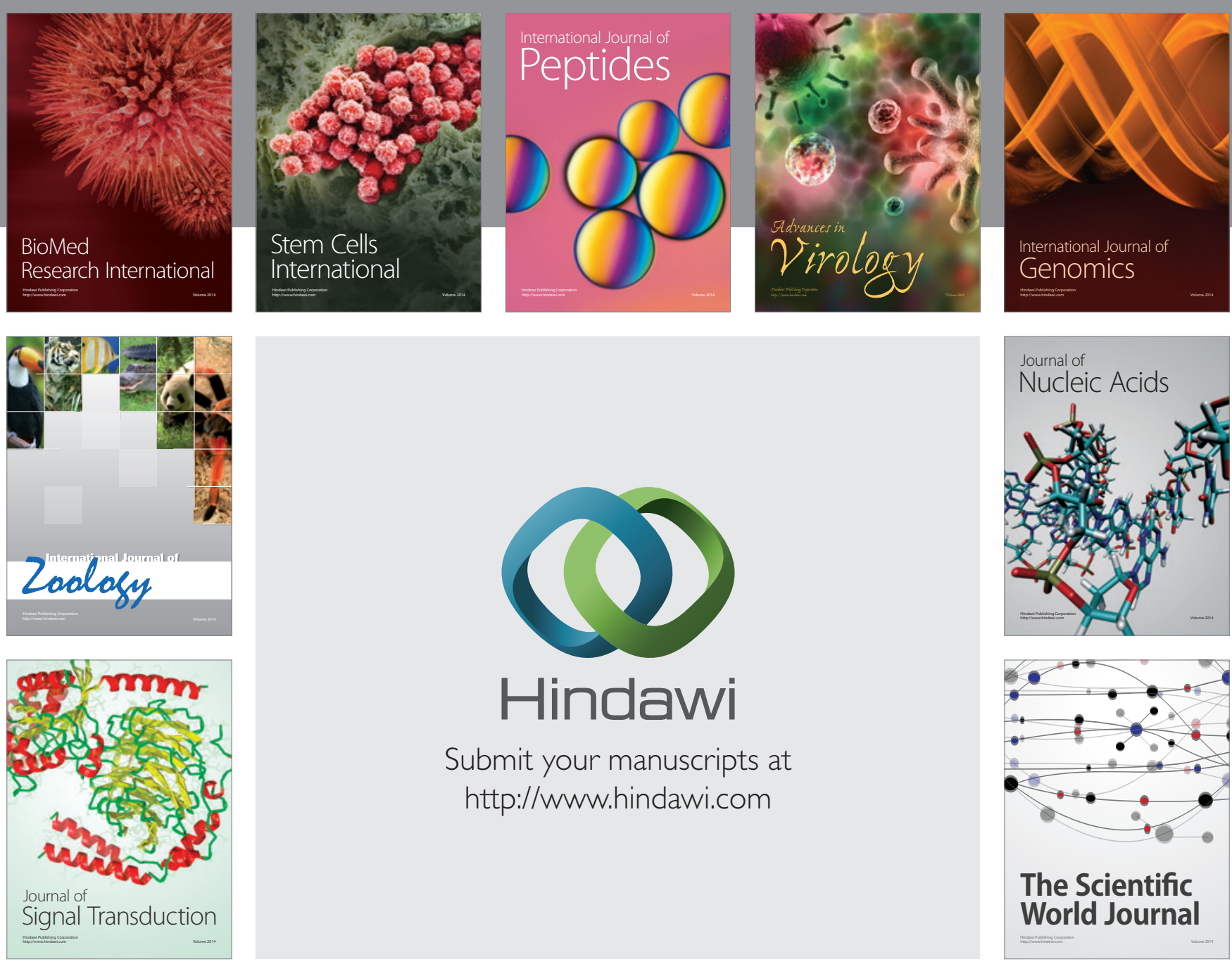

Submit your manuscripts at

http://www.hindawi.com
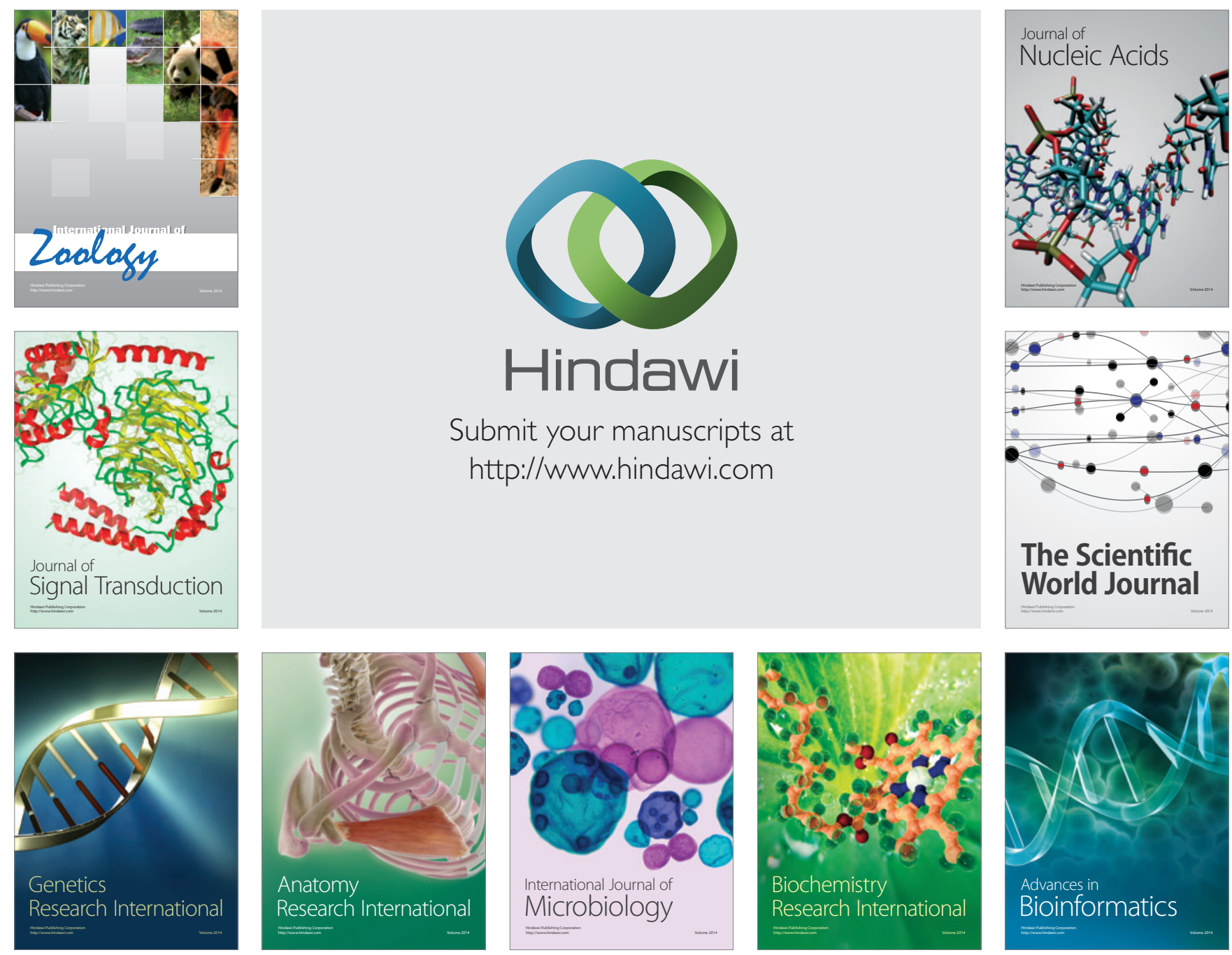

The Scientific World Journal
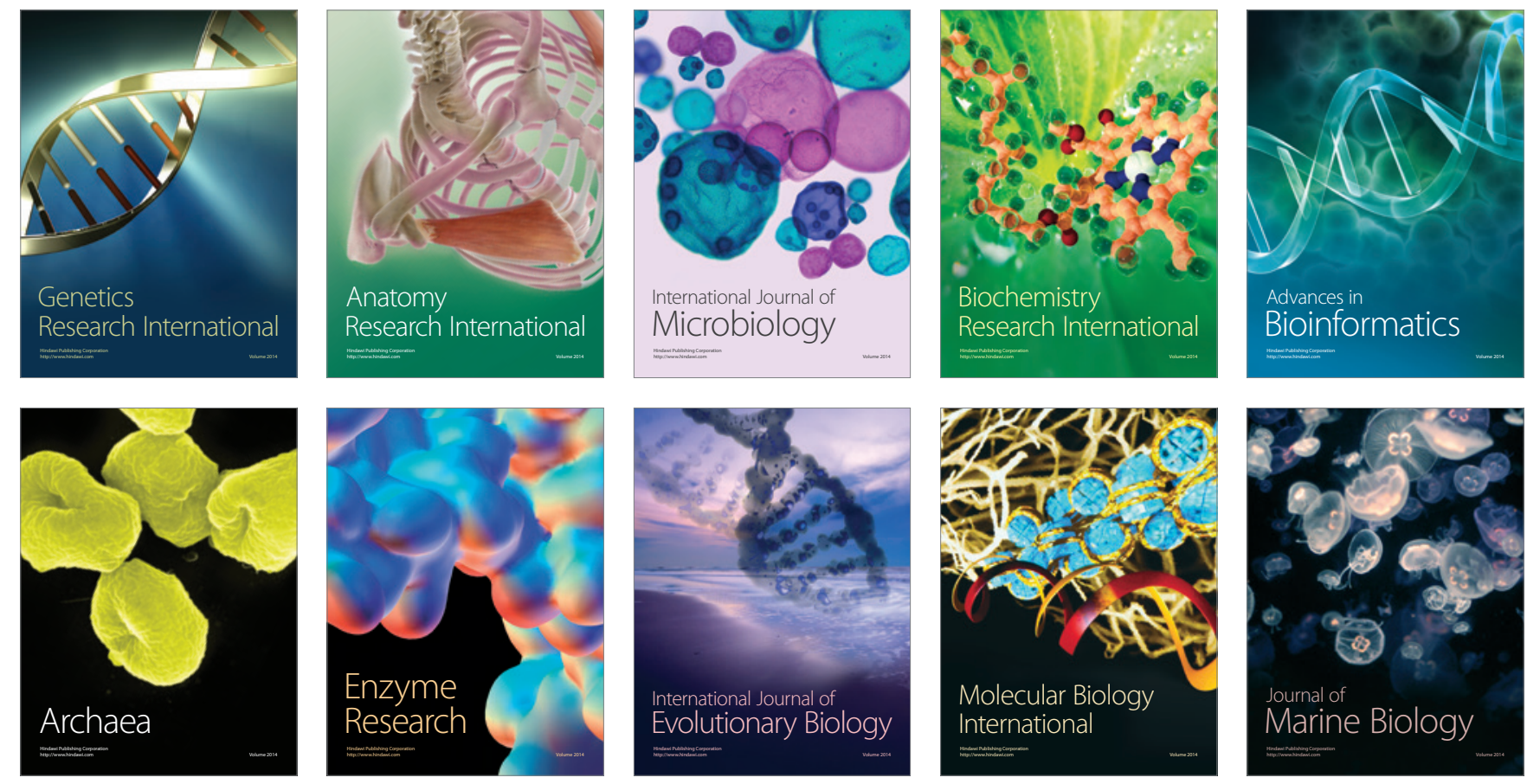